\title{
Correction to: The Big 5 Personality Traits and Willingness to Justify Unethical Behavior-A Cross-National Examination
}

\author{
Aditya Simha ${ }^{1} \cdot$ K. Praveen Parboteeah ${ }^{2}$
}

Published online: 28 March 2019

๑) Springer Nature B.V. 2019

Correction to: Journal of Business Ethics https://doi.org/10.1007/s10551-019-04142-7

The name of the second author was incorrect in the initial online publication. The original article has been corrected.

Publisher's Note Springer Nature remains neutral with regard to jurisdictional claims in published maps and institutional affiliations.

The original article can be found online at https://doi.org/10.1007/ s10551-019-04142-7.

Aditya Simha

simhaa@uww.edu

K. Praveen Parboteeah parbotek@uww.edu

1 University of Wisconsin - Whitewater, Management, 809 W Starin Rd, Whitewater, WI 53190, USA

2 University of Wisconsin - Whitewater, Management, 800 West Main Street, Whitewater, WI 53190, USA 